\title{
LATENCIES OF REM SLEEP AND AWAKENING IN MAJOR DEPRESSION : POSSIBLE INDICATORS OF CHOLINERGIC ACTIVITY
}

\author{
R. MACHOWSKI ${ }^{1}$, M. ANSSEAU ${ }^{2}$, G. CHARLES ${ }^{1}$, M. SCHITTECATTE ${ }^{1}$ \\ and J. WILMOTTE ${ }^{1}$ \\ ${ }^{1}$ Hôpital Vincent-Van-Gogh, 55, rue de l'Hôpital, B-6030 Charleroi, Belgium; ${ }^{2}$ Unité de Psychiatrie \\ Biologique et de Psychopharmacologie, CHU Sart Tilman, B-4000 Liège, Belgium
}

(Received 14 October 1988; accepted 10 August 1989)

\begin{abstract}
Summary - REM latency and awakening latency were analyzed in a sample of 26 major depressive inpatients and 8 male controls recorded for two consecutive nights. A significant inverse relationship appeared between REM latency and awakening latency in depressed patients. The relationship was more marked in male than in female patients. No significant correlation between REM latency and awakening latency was observed in male healthy volunteers. The hypothetical cholinergic supersensitivity in major depression is proposed to explain the present relationship. These results suggest that awakening latency might also be taken into account in the evaluation of sleep disturbances in depressive illness.
\end{abstract}

\section{REM latency / awakening / depression}

Résumé - Latences de sommeil paradoxal et d'éveil dans les dépressions majeures: indicateurs possibles d'activité cholinergique. La latence de sommeil paradoxal et la latence d'éveil ont été mesurées dans un échantillon de 26 patients hospitalisés présentant un épisode dépressif majeur et dans un groupe contrôle de 8 hommes. L'EEG de sommeil a été enregistré pendant 2 nuits consécutives. Nous avons mis en évidence une relation inverse entre la latence de sommeil paradoxal et la latence d'éveil chez les patients déprimés et plus particulièrement chez les hommes. Aucune corrélation significative entre ces paramètres n'est apparue au sein du groupe de volontaires masculins. Nous proposons, comme hypothèse explicative de cette relation, l'hypersensibilité cholinergique mise en évidence par certains auteurs dans les dépressions majeures. Ces résultats préliminaires semblent indiquer que la latence d'éveil est un paramètre dont on pourrait tenir compte dans l'évaluation des troubles du sommeil des patients déprimés majeurs.

latence de sommeil paradoxal / éveil / dépression

\section{Introduction}

It is now well established that major depressive disorders are characterized by various sleep EEG abnormalities: sleep continuity disturbances, reduced (or even suppressed) delta sleep, increased REM activity, and shortened REM latency (Kupfer and Thase, 1983; Reynolds and Kupfer, 1987). The shortening of REM latency seems to be the most specific feature of major depressive disorders (Kupfer, 1976). However, in some depressed patients, REM latency may show a great internight variability and fluc- 
tuate between very short and normal or even prolonged REM latencies (Ansseau et $a l ., 1985)$. The pioneer work of Sitaram and his group (Sitaram et al., 1976) has emphasized the role of cholinergic mechanisms in the induction of REM sleep. In healthy volunteers, physostigmine (an anticholinesterase agent), when infused during non-REM sleep, shortens the latency of the following REM period, while when infused during REM sleep, it provokes an awakening. Furthermore, higher doses of physostigmine injected during non-REM sleep also induce awakenings. These data suggest that non-REM sleep, REM sleep, and wake could reflect three steps of ascending acetylcholine (Ach) pressure.

In this context, the purpose of our study was to test such possible differences in Ach activity between REM sleep and wake by comparing REM latency with awakening latency, i.e. the time between sleep onset and the first wake period (Merica and Gaillard, 1985). Referring to the studies of Sitaram, we hypothesized that a greater Ach release superimposed on a supersensitive Ach receptor would induce more arousals. These arousals, especially as they occur prior to the first REM period, would delay REM sleep. We could then expect REM latency and awakening latency to be inversely correlated.

\section{Patients and Methods}

We studied 26 depressed patients consecutively admitted to the Sleep Laboratory Unit of Vincent Van Gogh Hospital, Marchienne-au-Pont, Belgium. All patients met DSM III criteria for a major depressive disorder (MDD) (American Psychiatric Association, 1980) after filling out the Schedule for Affective Disorders and Schizophrenia (Spitzer and Endicott, 1978). The scores of the Hamilton Rating Scale for Depression (24 items, NIMH version) ranged from $18-42$ with a mean $( \pm \mathrm{SD})$ of $25.1( \pm 5.9)$. This sample included 18 women and $8 \mathrm{men}$, ranging in age from 32 to $69 \mathrm{yr}$, with a mean age $( \pm \mathrm{SD})$ of $51.6( \pm 9.5) \mathrm{yr}$. Patients were free of medical illness and had a drug wash-out period of at least two weeks before sleep recordings. Our control group included 8 males, ranging in age from 22-48 yr with a mean age $( \pm$ SD) of $32.5( \pm 9.7)$ yr. These paid volunteers were free of medical or psychiatric illness.

After two habituation nights, EEG sleep was recorded for two consecutive nights and was scored according to the criteria of Rechtschaffen and Kales (1968). Sleep onset was defined as the first epoch (30 s) of stage 2 (Schultz et al., 1979). We used two different definition criteria to assess REM latency. On the one hand, REM latency (RL) was the time between sleep onset and the first epoch (30 s) of REM sleep (Knowles et al., 1982). On the other hand, REM latency minus awakening (RLMA) was the time between sleep onset and the first epoch (30 s) of REM sleep minus any intervening wake (Knowles et al., 1982). Awakening latency (AL) was defined as the time between sleep onset and the first subsequent uninterrupted three-minute period of wake (Merica and Gaillard, 1985).

The relationship between AL and each REM latency (RL and RLMA) was assessed by Pearson's product-moment correlation coefficient for each night. The distributions of RL, RLMA and AL data were analyzed with Kolmogorov-Smirnov test for difference from normality. When data distribution was significantly different from normality, the data were logtransformed in order to normalize their distribution before calculating the correlation coefficients. 


\section{Results}

Individual values are presented in Tables I and II. A one-way analysis of variance (ANOVA) did not evidence any gender effect on RL ( $F=0.9018$, n.s.), RLMA $(F=0.7573$, n.s. $)$ and AL $(F=0.5991$, n.s. $)$ in MDD group.

On the one hand, patients and controls did not have significantly different mean values of RL (respectively $87.4 v 576.2 \mathrm{~min} ; F=0.3250$, n.s.) and RLMA (respectively

Table I. Individual values of REM latency (RL), REM latency minus awakening (RLMA) and awakening latency (AL) in major depressive patients.

\begin{tabular}{|c|c|c|c|c|c|c|c|c|c|}
\hline \multirow[b]{2}{*}{ PATIEAT } & \multirow[b]{2}{*}{ SEX } & \multirow[b]{2}{*}{ AG B } & \multirow[b]{2}{*}{ HDS } & \multicolumn{3}{|c|}{ NIGHT 1} & \multicolumn{3}{|c|}{ NIGHT 2} \\
\hline & & & & RL & RLMA & AI. & $\mathbf{R L}$ & BLMA & $A L$ \\
\hline 1 & $\mathbf{F}$ & 47 & 22 & 85 & 67.5 & 47 & 67 & 53.5 & 326 \\
\hline 2 & $\mathbf{F}$ & 56 & 24 & 194 & 88.5 & 45 & 206.5 & 72.5 & 16 \\
\hline 3 & $\mathbf{M}$ & 32 & 25 & 83 & 73 & 20.5 & 130.5 & 67 & 14 \\
\hline 4 & $M$ & 48 & 29 & 48.5 & 48 & 95 & $\star$ & $*$ & 48 \\
\hline 5 & $\boldsymbol{F}$ & 69 & 18 & 45.5 & 34 & 37.5 & 33.5 & 33.5 & 150 \\
\hline 6 & $M$ & 60 & 29 & 122 & 66.5 & 21 & $*$ & $*$ & 102 \\
\hline 7 & $\mathbf{F}$ & 63 & 28 & 14 & 13 & 86 & 15.5 & 14.5 & 21.5 \\
\hline $\mathbf{B}$ & $\mathbf{F}$ & 56 & 29 & 60 & 55.5 & 33 & 5 & 5 & 29 \\
\hline 9 & $\mathbf{F}$ & $51 \div$ & 25 & 53.5 & 53 & 270 & 59.6 & 59.5 & 404 \\
\hline 10 & $\mathbf{H}$ & 51 & 25 & 52.5 & 52 & 150 & ** & $* *$ & *** \\
\hline 11 & $\mathbf{F}$ & 49 & 18 & 90.5 & 89 & 95.5 & 74.6 & 72 & 263.5 \\
\hline 12 & $\boldsymbol{F}$ & 39 & 42 & 36 & 36 & 66.5 & 47 & 47 & 61.6 \\
\hline 13 & $\boldsymbol{F}$ & 37 & 26 & 288 & 249 & 11 & 14 & 13.5 & 494 \\
\hline 14 & $\mathbf{F}$ & 49 & 23 & 50 & 49 & 54 & 286.6 & 113 & 15 \\
\hline 16 & F & 62 & 31 & 81.5 & 52.5 & 13 & 48.5 & 45 & 112 \\
\hline 16 & $F$ & 67 & 37 & 49.5 & 49 & 76 & 43.5 & 43 & 235.5 \\
\hline 17 & $\mathbf{p}$ & 62 & 28 & 54.5 & 22 & 17 & 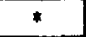 & $*$ & 60 \\
\hline 18 & M & 66 & 23 & 38.5 & 38.5 & 51.5 & 27.5 & 27.5 & 173.5 \\
\hline 19 & $M$ & 46 & 18 & 105 & 60 & 26 & 44.5 & 44 & 163.6 \\
\hline 20 & H & 65 & 18 & 29.5 & 27.5 & 271 & 22 & 22 & 430 \\
\hline 21 & M & 44 & 19 & 43.5 & 43.5 & 349 & $*$ & $*$ & 257.6 \\
\hline 22 & $\mathbf{F}$ & 45 & 18 & 200.5 & 76 & 14 & 29 & 29 & 312.6 \\
\hline 23 & $\mathbf{F}$ & 43 & 20 & 89 & 75.5 & 71.5 & *** & $* *$ & $* *$ \\
\hline 24 & $\mathbf{F}$ & 49 & 29 & 165.5 & 78 & 20.5 & 5 & 5 & 292 \\
\hline 26 & $\mathbf{p}$ & 63 & 25 & 50.5 & 50.5 & 66 & 132.5 & 96.5 & 28.5 \\
\hline 26 & $\mathbf{F}$ & 44 & 25 & 81.5 & 74.5 & 70.5 & 94 & 78.5 & 75 \\
\hline \multicolumn{2}{|c|}{$\underset{( \pm \mathbf{S D})}{\operatorname{MBAN}}$} & $(91.6$ & $\begin{array}{r}25.1 \\
(5.9)\end{array}$ & $\begin{array}{c}85.1 \\
(63.0)\end{array}$ & $\begin{array}{c}62.3 \\
(42.8)\end{array}$ & $\begin{array}{c}79.9 \\
(87.1)\end{array}$ & $\begin{array}{c}68.8 \\
(71.8)\end{array}$ & $\begin{array}{c}47.1 \\
(29.8)\end{array}$ & $\begin{array}{c}169.3 \\
(147.5)\end{array}$ \\
\hline
\end{tabular}

* No REM sleep occurred.

** Only one night available (due to technical failure). 
60.9 vs $73.9 \mathrm{~min} ; F=1.2991$, n.s.). On the other hand, AL was significantly shorter in depressed patients than in controls (respectively $122.8 v s 304.1 \mathrm{~min} ; F=22.9195$, $P<.001$ ).

As shown in Table III, statistically significant correlations were observed between $\mathrm{RL}$ and $\mathrm{AL}$ in the group of MDD patients $(r=-0.59, P=0.001$ for night $1 ; r=-0.63$, $P=0.003$ for night 2 ). The correlation was less important between RLMA and AL, but the coefficients remained statistically significant $(r=-0.41, P<0.04$ for night 1 ; $r=-0.44, P=0.05$ for night 2).

Table II. Individual values of REM latency (RL), REM latency minus awakening (RLMA) and awakening latency (AL) in healthy male volunteers.

\begin{tabular}{|c|c|c|c|c|c|c|c|c|}
\hline \multirow[b]{2}{*}{ VOLUNTEER } & \multirow[b]{2}{*}{ SEX } & \multirow[b]{2}{*}{ AGE } & \multicolumn{3}{|c|}{ NIGHT 1} & \multicolumn{3}{|c|}{ NIGHT 2} \\
\hline & & & HL & RLMA & AL & $\mathbf{R L}$ & RLMA & $A \mathrm{~L}$ \\
\hline 1 & $M$ & 25 & 62 & 60.5 & 159.5 & 52.5 & 51 & 435.5 \\
\hline 2 & $M$ & 25 & 61.5 & 61.5 & 348 & 157 & 155 & 248.5 \\
\hline 3 & $M$ & 32 & 57.5 & 53 & 434.5 & 52.5 & 50 & 256.5 \\
\hline 4 & $\mathbf{M}$ & 48 & 82 & 80.5 & 216 & 77 & 76.5 & 455 \\
\hline 5 & $M$ & 39 & 64 & 61.5 & 444.5 & 54 & 41.5 & 3.5 \\
\hline 6 & M & 43 & 38 & 37.5 & 415.5 & 64 & 58 & 441 \\
\hline 7 & $M$ & 26 & 188.5 & 181.5 & 174 & 90 & 81.5 & 66.5 \\
\hline 8 & M & 22 & 78 & 77.5 & 410 & 70.5 & 69.5 & 356.5 \\
\hline \multicolumn{2}{|c|}{$\begin{array}{l}\text { MEAN } \\
( \pm \text { SD })\end{array}$} & $\begin{array}{r}32.5 \\
(9.7)\end{array}$ & $\begin{array}{c}78.9 \\
(46.2)\end{array}$ & $\begin{array}{c}76.7 \\
(44.4)\end{array}$ & $\begin{array}{c}325.2 \\
(122.1)\end{array}$ & $\begin{array}{c}77.2 \\
(34.9)\end{array}$ & $\begin{array}{c}72.9 \\
(35.9)\end{array}$ & $\begin{array}{c}282.9 \\
(173.2)\end{array}$ \\
\hline
\end{tabular}

Table III. Correlations between REM latencies and awakening latency among major depressive patients and healthy male volunteers: Pearson's $r$.

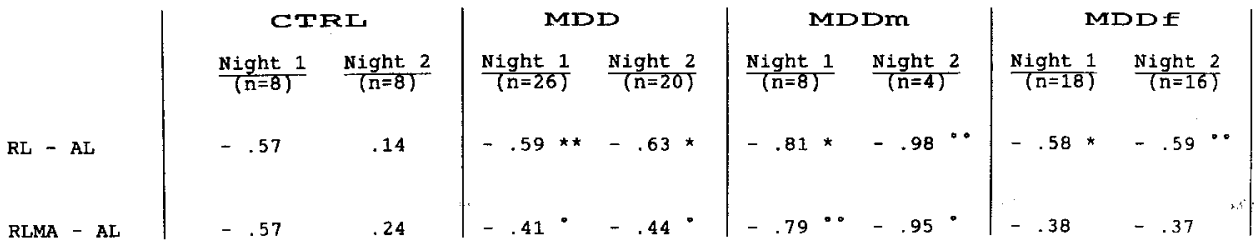

${ }^{\circ} P \leqslant 0.05 ;{ }^{\circ 0} P=0.02 ; * P \leqslant 0.01 ; * * P=0.001$. 
No significant correlation between either RL or RLMA and AL was found in our group of male controls (all $P$ values non significant). On the contrary, high and significant negative correlations exist between RL or RLMA and AL in male depressive patients (all $P$ values $<0.05$ ). The correlations were much weaker in the female MDD group ( 2 out of $4 P$ values $<0.05$ ).

The relationship between age and REM latency was not clearly established in our sample of patients. While the relationship between RL and age was not significant $(r=-0.23$, n.s.), RLMA and age were significantly correlated $(r=-0.33, P<0.03$ ). Normal volunteers did not evidence any significant correlation either between RL and AL ( $r=-0.29$; n.s.) or between RLMA and AL ( $r=-0.30$; n.s.).

No correlation appeared between $\mathrm{AL}$ and age in both groups $(r=0.04$, n.s. in MDD group; $r=-0.04$, n.s. in control group).

\section{Discussion}

These preliminary results show a statistically significant inverse relationship between REM latency and awakening latency in depressive patients, suggesting that a short REM latency may be accompanied by a long awakening latency, while a prolonged REM latency may be associated with a short awakening latency. This relationship was particularly more marked in male patients than in female patients. Such a relationship was not evidenced in our group of 8 male controls. This is in accordance with the data of Merica and Gaillard (1985) who did not report any correlation between RLMA and AL in normal volunteers of both sex.

The relationship we found could support the role of cholinergic mechanisms in the regulation of both wake and REM sleep.

Koella (1984) described the cholinergic mechanisms as vigilance-enhancing instruments in higher-function systems. Ach (or its agonists) induces all signs of cortical arousal, whereas its antagonists have the opposite effects; moreover, Ach release remains at high levels during REM sleep and wake, while it decreases during slow wave sleep.

In a general way, Ach agonists decrease REM latency and Ach antagonists increase REM latency (see review in Sitaram et al., 1984, and Dilsaver, 1986). Sitaram and his group have shown that the response to cholinergic agents was more marked in depressives as compared to normals, suggesting the existence of a cholinergic supersensitivity in depression (Sitaram et al., 1980; Jones et al., 1985). In the studies comparing normals with depressives, these authors infused cholinergic agents during the second non-REM period, since the first non-REM period of depressed is short. Indeed, it has been shown that the REM-to-REM intervals and the non-REM periods subsequent to the first are normal in depressed patients. In contrast, Berger et al. (1983) infused physostigmine during the first non-REM period in depressed patients and in normal volunteers. REM latency during baseline was significantly shorter in 
depressives than in controls. While physostigmine significantly shortened REM latency in normals, it provoked no further significant reduction of REM latency in depressed patients, but it awakened the majority of patients.

These data suggest that wake and REM sleep could be two steps of an arousal process regulated by cholinergic mechanisms. Beyond a hypothetical threshold, Ach activity would induce wake. REM latency and awakening latency could then reflect the interaction between Ach release and cholinergic sensitivity in the central nervous system. As mentioned above, a short REM latency is considered to be related to cholinergic supersensitivity. We suggest that if an increase in Ach release is superimposed on that cholinergic supersensitivity, it induces higher arousal and thus a propension to awakening rather than REM sleep. Therefore, wake would tend to occur early and before REM sleep. Such fluctuations of Ach activity could then explain the internight variability of REM latency in some depressed patients.

However, as REM sleep and wake are not under a unique cholinergic control, the present findings should be developed in a more global theory involving different neurotransmitter systems (Koella, 1984; Hobson et al., 1986).

Finally, we have to mention the fact that two of our controls had at least one short REM latency. Like all our volunteers, these two subjects did not have any personal or familial history of either sleep disturbances of psychiatric disorders. No change in their life occurred during the study, except the fact that they had to sleep in the laboratory. Schulz and Lund (1983) found an even higher rate of short REM latencies in healthy volunteers, as 3 out of their 10 controls had at least one sleep onset REM episode (SOREM). Constitutional (or unexpectedly induced by experimental conditions) small amplitude circadian rhythms were proposed as a possible explanation of this phenomenon.

In conclusion, despite their need to be confirmed in a larger sample, these preliminary results suggest that awakening latency might be taken into account in parallel with REM latency when evaluating sleep EEG disturbances in depressed patients. Moreover, it seems that both parameters could be partially related to common cholinergic mechanisms.

\section{Acknowledgments}

Our gratitude is due to R. Roldan, for his generous assistance in data management; and to Dr. A.F. Crine and the sleep laboratory staff for their help in sleep recordings.

\section{References}

American Psychiatric Association (1980) DSM-III : Diagnostic and Statistical Manual of Mental Disorders. APA, Washington, DC, 3rd edn

Ansseau M., Kupfer D.J. \& Reynolds III C.F. (1985) Internight variability of REM latency in major depression: implications for the use of REM latency as a biological correlate. Biol. Psychiatry 20, 489-505 
Berger M., Lund R., Bronisch T. \& Von Zerssen D. (1983) REM latency in neurotic and endogenous depression and the cholinergic REM induction test. Psychiatry Res. 10, 113-123

Dilsaver S.C. (1986) Pharmacologic induction of cholinergic system up-regulation and supersensitivity in affective disorders research. J. Clin. Psychopharmacol. 6, 65-74

Hobson J.A., Lydic R. \& Baghdoyan H.A. (1986) Evolving concepts of sleep cycle generation : from brain centers to neuronal populations. Behav. Brain Sci. 9, 371-448

Jones D., Kelwala S., Bell J., Dube S., Jackson E. \& Sitaram N. (1985) Cholinergic REM sleep induction response correlation with endogenous depressive subtype. Psychiatry Res. 14, 99-110

Knowles J.B., MacLean A.W. \& Cairns J. (1982) Definitions of REM latency: some comparisons with particular reference to depression. Biol. Psychiatry 17, 993-1002

Koella W.P. (1984) Neurotransmitters and sleep-a synthesis. In: Sleep '84, 7th Eur. Congr. Sleep Res., Munich 1984 (Koella W.P., Rüther E. \& Schultz H., eds.), Gustav Fischer Verlag, Stuttgart, New York, pp. $28-39$

Kupfer D.J. (1976) REM latency : a psychobiologic marker for primary depressive disease. Biol. Psychiatry $11,159-174$

Kupfer D.J. \& Thase M.E. (1983) The use of the sleep laboratory in the diagnosis of affective disorders. Psychiatr. Clin. N. Am. 6, 3-25

Merica H. \& Gaillard J.M. (1985) Statistical description and evaluation of the interrelationships of standard sleep variables for normal subjects. Sleep 8, 261-273

Rechtschaffen A., Kales A.A. (1968) A Manual of Standardized Terminology, Techniques, and Scoring System for Sleep Stages of Human Subjects. Public Health Service, US Government Printing Office, Washington, DC

Reynolds C.F. \& Kupfer D.J. (1987) Sleep research in affective illness: state of the art circa 1987. Sleep $10,199-215$

Schultz H., Lund R., Cording C. \& Dirlich G. (1979) Bimodal distribution of REM sleep latencies in depression. Biol. Psychiatry 14, 595-600

Schultz H. \& Lund R. (1983) Sleep onset REM episodes associated with circadian parameters of body temperatures. A study in depressed patients and normal controls. Biol. Psychiatry 18, 1411-1426

Sitaram N., Wyatt R.J., Dawson S. \& Gillin J.C. (1976) REM sleep induction by physostigmine infusion during sleep. Science 191, 1281-1283

Sitaram N., Nurnberger J.I., Gershon E.S. \& Gillin J.C. (1980) Faster cholinergic REM sleep induction in euthymic patients with primary affective illness. Science 208, 200-202

Sitaram N., Gillin J.C. \& Bunney W.E. (1984) Cholinergic and catecholaminergic receptor sensitivity in affective illness: strategy and theory. In: Neurobiology of Mood Disorders (Post R. \& Ballenger J., eds), Williams and Wilkins, Baltimore, pp. 629-651

Spitzer R.L. \& Endicort J. (1978) A diagnostic interview: the schedule for affective disorders and schizophrenia. Arch. Gen. Psychiatry 35, 837-844 